\title{
Research on Construction of Female Image and Female Consciousness by Television Media
}

\author{
Luo Jinyi \\ HongKong Baptist University, Hong Kong, China, 999077 \\ hunter2011@foxmail.com
}

Keywords: Female image; Female consciousness;Television media.

\begin{abstract}
This paper uses the content analysis method and analyzes the age, occupation, education level and role image of female guests invited by"Luyuyouyue"from 2010 to 2014. From the perspectives of gender ratio, age distribution, education level, professional image and on-camera reasons, this paper presents the construction of female image and female consciousness by television media after 2010 .
\end{abstract}

\section{Introduction}

Before the arrival of the mass media, the traditional media has a number of stereotypes. It turns the sex into gender and believes the lower status of women only existing in families. In a male dominated society, women are materialized as a sex object, become the plaything of men and accessoriesin meeting the needs of male. Men will always be successful, leading, pioneers, women can only use to when the vase with a beautiful young pleasing others. Since twenty-first Century, the law and policy on the women's liberation, to encourage women's economic independence, women and men and women's equality, the full realization of the dominant female discourse. The media has an important social responsibility in the awakening of female consciousness.

\section{Materials and Method}

This study uses content analysis method. In the field of news media, newspapers, magazines, radio, television, the Internet, as the medium of communication, the five media, in shaping the image of women, and the construction of female ideology has an important impact. Especially through the mass media channels, the female image of the TV programs, but also can reflect the current social mainstream cultural values. Therefore, the "Luyuyouyue" program as an analysis of the text, but also helps us to fully understand the cultural traditions, values, behavior, lifestyle, and so on. "Luyuyouyue" is a television talk show. The theme of the content of each program is enacted in accordance with the host to invite the guests. These guests, whether star, public figures or ordinary people, have a social model of the effect, can communicate the need to build a sense of discourse. In the 2010-2014 broadcast of the "Luyuyouyue" all the shows, the female guests as the research object, for each woman in accordance with the following four indicators for classification and encoding. These four indicators are:

1. Ageis divided into: 0-10 years old, 10-20 years old, 20-30 years old, 30-40 years old, 40-50 years old, over 50 years old.

2. Education level is divided into: primary school and below, junior middle school, high middle school and technical secondary school, college above, unknown.

3. Occupation is divided into star (actor, singer and anchor), high-tech personnel, special professionals, students, and ordinary persons.

4. Role image is divided into personal achievement, team achievement, noble character, and life experience four categories.

Time variable is divided into 5 years, that is, 2010, 2011, 2012, 2013, and 2014. According to the 5 years of the "Luyuyouyue" the broadcast of the number of sets to make statistics, including a set of three on the next phase of the program, repeat broadcast programs, clip broadcast programs, etc.. 


\section{Results and Analysis}

Sex Ratio. The gender ratio of invitees in Luyuyouyue from 2010 to 2014 is shown as Figure 1.

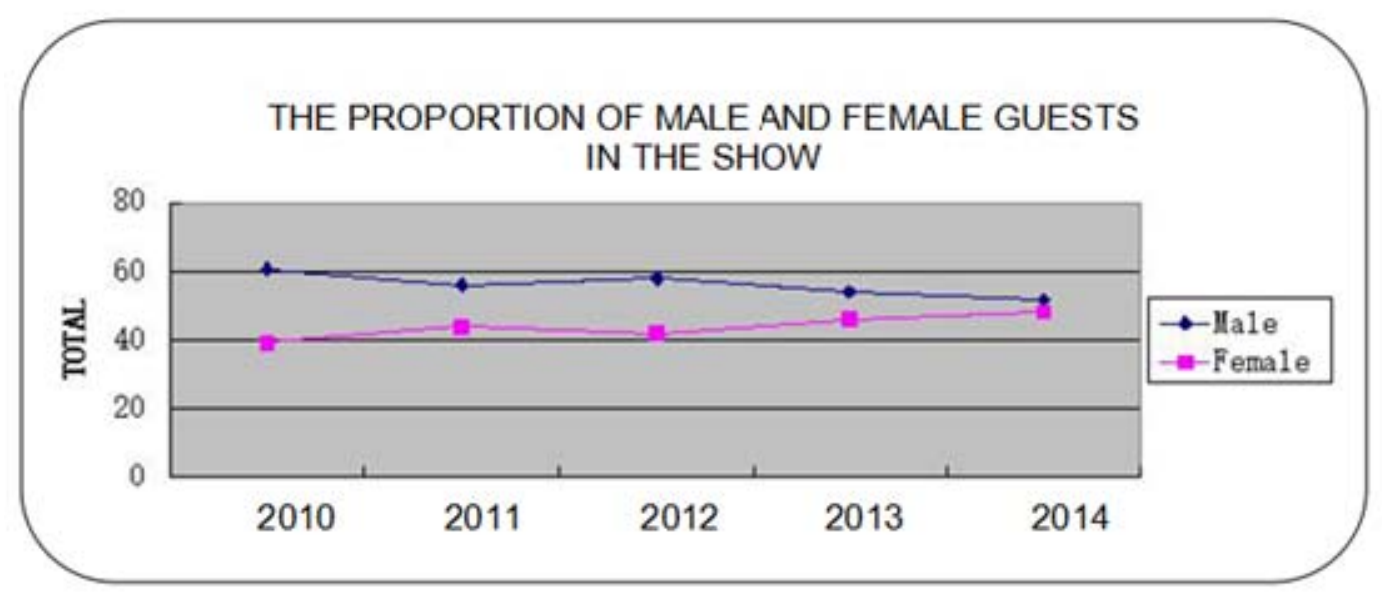

Fig. 1 Proportion of male and female guests in the show

According to figure 1, we found that the program in five years, the invitation of the male guests significantly more than female guests. But with the time change, the number of men and women has narrowed. In China for thousands of years of traditional culture, is the center of male power is the social and cultural value system. The position of the female role in the weak group, life must obey the male domination and domination. The discourse power of male ideology controls the position of the whole society. In the investigation of the guests, there is no lack of a lot of female guests as a male guest with, or a family with the program. Such as gymnastics champion Zou Kai's girlfriend, Liu Guoliang, the wife of table tennis player with their participation in the program. Although China's current status of women's life, social status has been improved, but still did not achieve the true equality of men and women.

Age Distribution. Analysis of the "Luyuyouyue" program in the female guests of different age distribution, can better positioning the role of female image. From the overall situation of the several years, the age distribution of the female guests is basically stable, which shows that the social period has no major changes. Here is the number of people in this study.

Table 1 Age distribution of female invitees in the show (\%)

\begin{tabular}{|c|c|c|c|c|c|}
\hline & 2010 & 2011 & 2012 & 2013 & 2014 \\
\hline 0 -10 years old & 2.3 & 1.1 & 2.5 & 7.4 & 8.2 \\
\hline 10-20 years old & 6.4 & 2 & 3.1 & 8 & 9.1 \\
\hline 20-30 years old & 7.3 & 6.7 & 13.5 & 24.8 & 16.7 \\
\hline 30-40 years old & 48.8 & 45.2 & 26.5 & 30.4 & 38.5 \\
\hline 40-50 years old & 23.3 & 30.6 & 23 & 20.3 & 20 \\
\hline over 50 years old & 11.9 & 13.4 & 31.4 & 9.1 & 7.5 \\
\hline
\end{tabular}

From table 1, we can see that, in the 10 program, female guests as a typical female image of the new era, the age is mainly concentrated in the age of 30-40 years, 20-30 years, 40-50 years of age, three gold age. Under the age of 20, there are mainly students in the crowd, including a special talent of the children, as well as to follow the parents, with the program. Over 50 years of age, the number of female guests in 2012 is more. The number of other years is less. And the three golden age, but also the female body and mind development, life happiness, the important period of career. In this process, there are outstanding students abroad, successful business woman, outstanding character as an understanding wife and loving mother. So this is the most representative of the 
image of women in the new era and as a social model, the model of learning was invited appearance, through the television media to convey the female values.

Education Level. The result is shown as follows:

Table 2 Education level of female invitees in the show (\%)

\begin{tabular}{|c|c|c|c|c|c|}
\hline & 2010 & 2011 & 2012 & 2013 & 2014 \\
\hline $\begin{array}{c}\text { primary school } \\
\text { and below }\end{array}$ & 3.5 & 7.4 & 8.7 & 15.9 & 8.7 \\
\hline $\begin{array}{c}\text { junior middle school } \\
\text { high middle school } \\
\text { and technical school }\end{array}$ & 7.3 & 5.7 & 12.6 & 9 & 9 \\
\hline college above & 40.5 & 45 & 39 & 42.6 & 45.7 \\
\hline unknown & 5.6 & 4.3 & 4.4 & 3.5 & 2.7 \\
\hline
\end{tabular}

Compared to the past, the modern society's new women do not have to simply by the traditional "woman is not only Germany" this idea. Table 3 shows that these are the representatives of successful people, but also on the knowledge and culture. On the other hand, a part of the older women will be in order to better work in a timely manner to enhance their knowledge reserves to continue education. There are also some people who suffer from low cultural education mainly because of family poverty, or physical disability and other objective factors to give up the right to education. Although the education level of the part of the female invitees is not high, they still self-learn and strive to struggle.

Professional Image. The result is shown as follows:

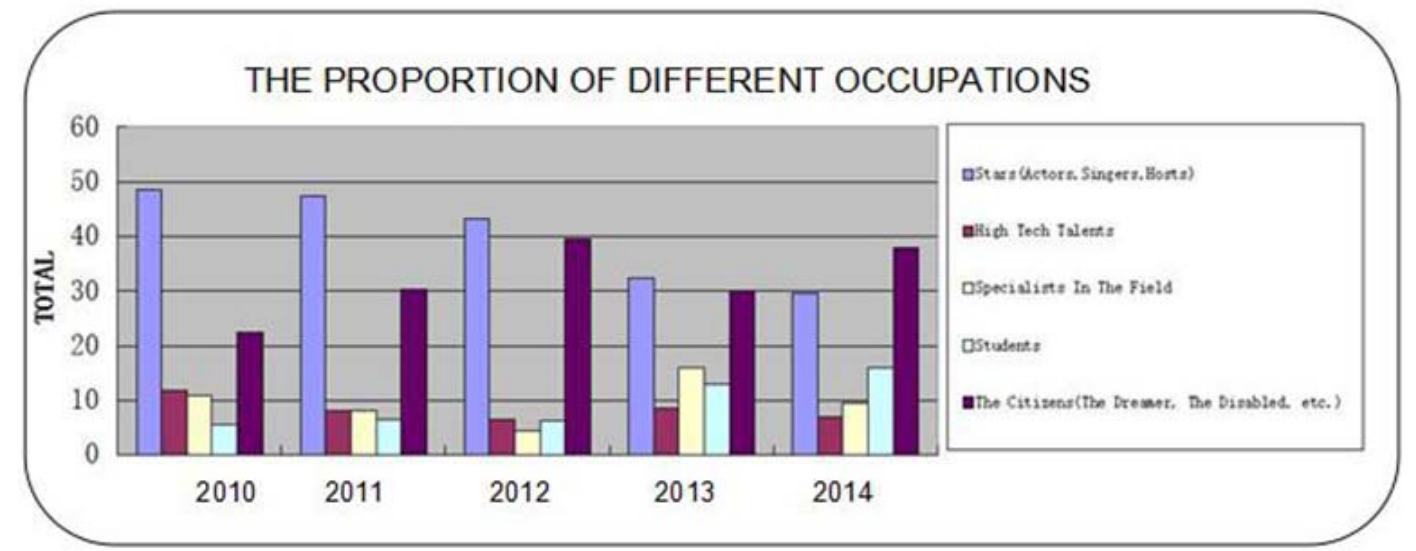

Figure 2 Proportion of different occupations

From the results of the five years of statistical results, "Lu Yu has about" the female guests involved in the program, the professional image of a wide range of professional image. As a talk show program, in order to see and ratings, as well as the general public to get a consensus, the program more choice of female star as a guest. The depth interviews that the public have known to the public as well as the depth of the background to attract the audience's attention. In addition, the image of the female guests as part of the general public. Including ordinary but continue to adhere to the dreamer, and life are difficult to take care of themselves but smile to the life of people with disabilities. Therefore, female guests in the selection, no longer limited to the star, in-depth to various fields, such as high-tech personnel, special skills, students, etc.

On-camera Reasons. A variety show aims of transferringpositive energy to the society. The invited guests must create positiveviews, excellent quality of the new era of women. The statistical analysis of the female images is as follows: 
THE SOURCE OF SHOWING

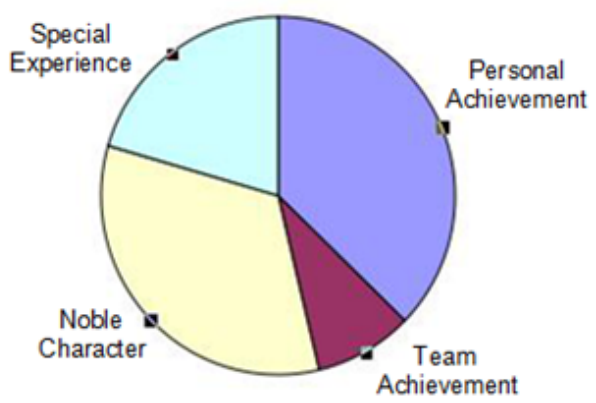

Fig. 3 Source of showing

From Fig. 3, we can find that the reasons of female guest appearance are mainly distributed in the four aspects, personal achievement, team achievement, noble qualities and special experience. TV media publicity and shaping the image of women, is no longer dependent on men's accessories, and more is and women's own development, to strengthen the subject consciousness of new era female role. In their middle and even become the industry elite, there is no need for the existence of material dependence, they have their own business. Through personal efforts to achieve the attention of the achievements and the noble character of the female is the program to invite the main object. Special experience of women has also relatively large numbers of people, including women entrepreneurs, the fight against disease, etc. these ordinary people can't experience the story based, with a special story to attract audiences.

\section{Conclusion}

From the five aspects of sex ratio, age distribution, level of education, professional image and on-camera reasons, this paper analyzes the female image and female consciousness of invited female guests in"Luyuyouyue" program. On the whole, the results of all the statistics show that the new changes of the society give a new meaning to the female image. The popularity of TV media, so that the value of the spread of the concept to allow more people to accept. The TV media not only charters the external image, but also focus on the connotation of the extension, guiding females to healthy development.

\section{References}

[1] X. Liang, The Effect of Gender Difference of The Host on the TV Talk Show Conversation Mechanism the Contrast Analysis between YishuRenshengand Luyuyouyue Programs, Central China Normal University, 2014.

[2] X.Q. Meng, On the Female Tragedy Consciousness in Li Shaohong's Movie and TV Plays, Journal of Baoji University of Art s and Sciences (Social Sciences), 2(2007):79-82.

[3] Q. Qi, Female Consciousness in TVDrama and the Narrative Strategies of Female Screen writers from the Perspective of Mass Culture, Journal of Shanghai Normal University (Philosophy\&SocialSciencesEdition), 5(2014):109-115.

[4] Hao. Hua, The Evolution of Female Consciousness in TV Seriesduring the Transition Period, Soochow University, 2012. 